\title{
Demonstration of a Dynamic Braking System for Reduced Runaway Speed of Hydraulic Turbines
}

\author{
Urban Lundin ${ }^{1}$, Johan Bladh ${ }^{2}$ \\ ${ }^{1}$ Division of Electricity, Department of Engineering Sciences, Uppsala University, Uppsala, Sweden \\ ${ }^{2}$ Vattenfall AB, R \& D Projects, Department of Power Technology, Älvkarleby, Sweden \\ Email: Urban.Lundin@Angstrom.uu.se, Johan.Bladh@Vattenfall.com
}

How to cite this paper: Lundin, U. and Bladh, J. (2017) Demonstration of a Dynamic Braking System for Reduced Runaway Speed of Hydraulic Turbines. Journal of Power and Energy Engineering, 5, 46-57. https://doi.org/10.4236/jpee.2017.512007

Received: September 15, 2017

Accepted: December 8, 2017

Published: December 11, 2017

Copyright (c) 2017 by authors and Scientific Research Publishing Inc. This work is licensed under the Creative Commons Attribution International License (CC BY 4.0).

http://creativecommons.org/licenses/by/4.0/

\section{c) (i) Open Access}

\begin{abstract}
Reducing the overspeed during load rejection would benefit the mechanical and hydraulic systems in a hydropower station. This paper presents some selected results of a pilot installation of a dynamic braking system. The $4 \mathrm{MW}$ dump load was installed and tested on a $10 \mathrm{MW}$ Francis turbine unit. The results show that the overspeed reduction is obtained and compares well with simulation results. Further, a reduction in vibration levels is positive as well as the reduced time for stopping and possible resynchronization. It is argued that a similar system with continuous cooling could be used as an attractive alternative to spillway capacity.
\end{abstract}

\section{Keywords}

Dynamic Braking Resistor, Electrode Boiler, Hydropower Generator, Runaway Speed, Water Turbine

\section{Introduction}

A turbine-generator set that abruptly loses its load will accelerate due to the resulting torque imbalance, arising from the fact that the turbine torque is still active but the braking torque of the generator disappears quickly. Another scenario where there is a need of discharging water through the turbine without the electrical grid is when flooding has shut the grid down and there is a need to discharge water. Without an electrical load the turbine-generator unit would overspeed if the rated torque was applied from the runner. Such runaway situations expose the unit to severe mechanical stress and set the dimensioning constrains of many components. Well-known problems during runaways on hydraulic 
units are:

- Axial lift force on Kaplan turbines which can cause seal failure;

- Centrifugal forces which cause extreme loads on mechanical components such as dove tails;

- Difficulties to meet the fault ride trough requirements;

- High vibration levels due to turbine operating out of range;

- Extreme hydraulic water pressures caused by fast guide vane closing.

Common methods to limit the acceleration and reduce the maximum runaway speed involve increasing the inertia of the rotating system, fast guide vane closing, and if possible, delaying the opening of the generator circuit breaker a few seconds until the mechanical torque has been reduced. Increasing the shaft inertia requires more material, more rigid structures, and it increases bearing losses. Fast guide vane closing is restricted by hydraulic conditions such as the water hammer effect [1]. Delayed generator breaker opening is only applicable to internal mechanical faults.

Another solution is so called decompressing chambers where the flow to the turbine is redirected to another system that can handle the large mass flows. The decompression chambers also rely on a valve that could potentially malfunction, and needs additional waterways which can be costly.

For synchronous generators with a full power converter there is also the possibility to use regenerative braking, i.e. extracting electrical power at another frequency than rated and injecting it on the grid. However, the application of full power converters in power stations with hundreds of MW is not feasible in the nearest future.

\section{Dynamic Braking Systems}

Connecting a local resistive load is another option to reduce the runaway speed and decrease the time to re-synchronization or full stop, which would work also during loss of the external grid [2]. Dynamic braking resistors are widely used in combination with electric traction motors to reduce the speed of for instance electric vehicles, trains and elevators. Dynamic braking resistors have also been used for power system stability purposes [3] [4] [5] [6].

Although the basic principle is the same, the operating conditions are quite different, e.g., regarding voltage level, power and energy absorption. Braking resistors for grid stability applications are typically designed to operate at very high voltage and absorb large power, but only during parts of a second [7] [8] [9] [10] [11]. Bringing a train to stop takes much more time, but the voltage and power levels are much lower. Large hydropower units typically operate at high voltage levels, say $10-25 \mathrm{kV}$; they deliver several hundred MW of power; and it might take up to 10 seconds to close the guide vanes in case of a fault [12].

Motives for installing a dynamic braking resistor on a large power generating unit involve: 
- Reducing axial lift forces on Kaplan turbines.

- Reducing the time to stop or re-synchronization.

- Improving fault ride through capabilities.

- Reducing vibration levels, thus extending the life of sensitive components.

- Avoiding hydraulic transients by making it possible to close the guide vanes slower.

Despite the benefits of dynamic braking, information on and implementations of such systems are scarce in the literature and it is hard to find any experimental information. One reason for this is that the dynamic braking system cannot be used when a stator ground fault occurs. However, most faults are covered. Another reason is that it can be hard to select a suitable resistor that can handle the voltage and power needed. An attractive component can be a electrode boiler that is robust and relatively cheap, it can also be made totally passive. The electrode boiler braking system should be seen as a life-time extender of the original equipment.

In this article we present information from a full scale test of a dynamic braking system on a $10 \mathrm{MW}$ hydropower unit. The control system's handling of a load rejection will be detailed as well as the components used and results from load rejection tests.

\section{Method}

The idea of dynamic braking is represented in Figure 1. An external braking resistor, or dump-load (DL), is connected to the generator via a dedicated circuit breaker. This circuit breaker normally connects a bus bar with voltage to a load with no voltage. However, it does not have to break any large currents depending on how the magnetization system for the generator is responding during the connected sequence.

The control system has to be set up in a way so that the DL circuit breaker is not closed while the generator breaker is closed. Therefore, a few safety requirements were used in order to be able to connect the dump-load. The system was intended to reduce the over speed during load rejection so the requirements to signal the load rejection and activate the DL-breaker are:

1) The generator circuit breaker must be open;

2) The rotational frequency has increased above a threshold value;

3) The power output from the generator is zero, or the generator current is below a set value.

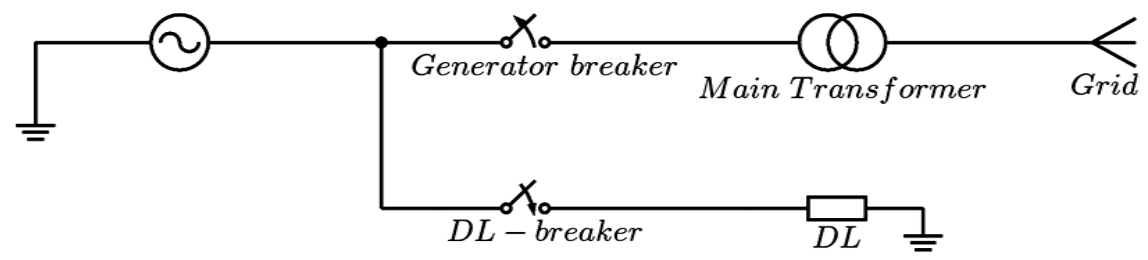

Figure 1. Circuit diagram for the electrical installation of the dynamic braking for a hydropower unit. $D L$ represents the dynamic braking dump load. 
When these criteria are fulfilled the dump-load circuit breaker can activate the dump-load. Criteria 2) or 3) can be exclusive. In the implementation described here both criteria were used in order to prevent unintentional connection of the dump-load.

\section{Simulation}

From the turbine efficiency curve and knowledge of the inertia of the rotating shaft a simple model based on the swing equation was set up describing the rotational energy and input of power from the turbine and output of power to the dump-load. The dump load was assumed to consume a constant power. However, this depends on the actions of the magnetization system during operation.

The speed can be simulated using the swing equation

$$
J \frac{\mathrm{d} \omega}{\mathrm{d} t}=\tau_{\text {turbine }}-\tau_{\text {generator }},
$$

where $\omega$ is the mechanical angular velocity. The inertia, $J$, was taken from the manufacturers data-sheet with info on the unit, added mass effects were neglected. The torque from the turbine, $\tau_{\text {turbine }}$ is taken from a Mussel-diagram giving the power versus flow characteristic of the turbine, and the generator torque, $\tau_{\text {generator }}$ is assumed to be the electrical torque calculated from the actual power of the unit. The unusual operation of the speed and flow conditions means that the turbine efficiency and energy uptake had to be extrapolated from the measurements.

Different size dump-loads were studied, but eventually a size of $4 \mathrm{MW}$ was decided on for the $10 \mathrm{MW}$ unit. A $10 \mathrm{MW}$ dump-load would mean that the speed increase would be negligible. The value $4 \mathrm{MW}$ was chosen to get a noticeable effect from the dump-load and considered to be a budget alternative for the load itself since this was a proof of concept. An electrode boiler was chosen as a robust and simple resistive element with reasonable thermal capabilities. The supplier has electrode boilers up to $50 \mathrm{MW}$, meaning that an up scaling is straightforward.

The power uptake of the electrode boiler is smooth and it reaches a steady state in a relatively short time.

The simulated over speed of the unit is shown in Figure 2, for different sizes of the dump-load. The load rejection from $10 \mathrm{MW}$ occur at $\mathrm{t}=0$, and the dump load is assumed to be activated at $T=T_{D L}=0.4 \mathrm{~s}$, when the conditions for activation are met. This time was assumed for the unit to accelerate from 50 to 52 $\mathrm{Hz}$ in the electrical measurement and the control system react and activate the dump-load switch.

The simulation was carried out by solving Equation (1) numerically by setting controlling the turbine power with the setting of the guide vane (and their closing) and assuming a constant output power to the grid and later to the dumpload. The simulation neglects losses and use the measured turbine data.

A dynamic braking system was implemented on a Hydropower unit in the 


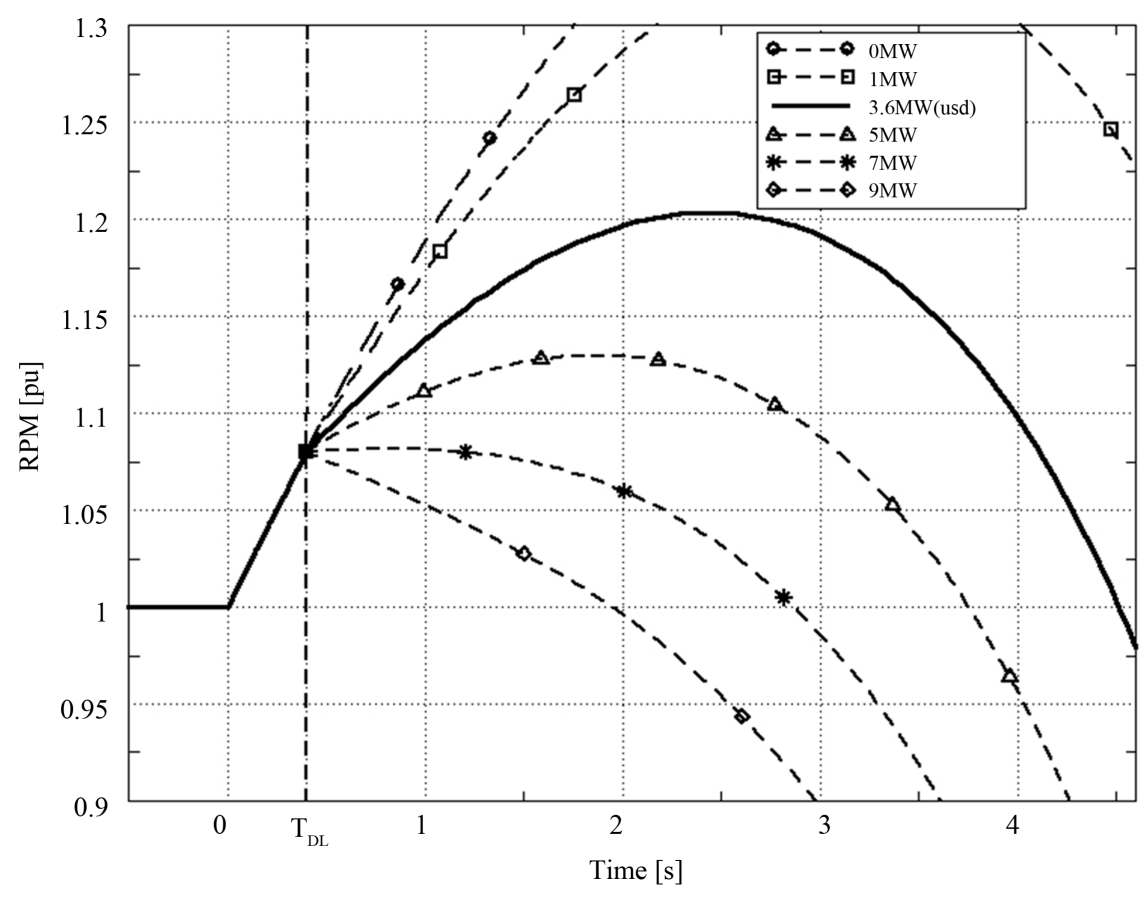

Figure 2. Simulation of the RPM of the unit under a load rejection sequence for different dump-load ratings. The dump load activates after the unit has accelerated from 50 to 52 $\mathrm{Hz}$, and the control system has activated the dump-load switch.

north of Sweden, shown in Figure 3. Data for the unit and dump-load found suitable is given in Table 1 . The ancillary braking resistor was connected as shown in Figure 1. New cables (bus bars) were installed from the generator terminals to the new dump-load breaker, then from the dump-load breaker to the dump-load itself. The control system was wired and implemented on a PLC, the ABB AC800M platform.

Connecting the generator to a resistive load makes it possible to deliver power at any rotational speed off the rated. The unit has two relay protections that measure rotational speed in order to detect faults: the frequency fault protection and the over voltage protection $(\mathrm{U} / \mathrm{f}>$ ). To keep the machine in operation with the dumpload connected, these two relays must be temporarily disabled. On the actual unit the field breaker had a over speed protection (to prevent over voltages) this was deactivated in order to keep the field breaker connected, so that the generator would be magnetized at all times.

When the criteria for the dump-load was met, the dump-load sequence followed:

1) Open generator breaker if it is not already open;

2) Close the field breaker if it is not already closed;

3) Deactivate protective functions in the unit control system if necessary;

4) Close the dumpload breaker;

5) Wait for shaft speed below threshold value for deactivation;

6) Open dumpload breaker. 


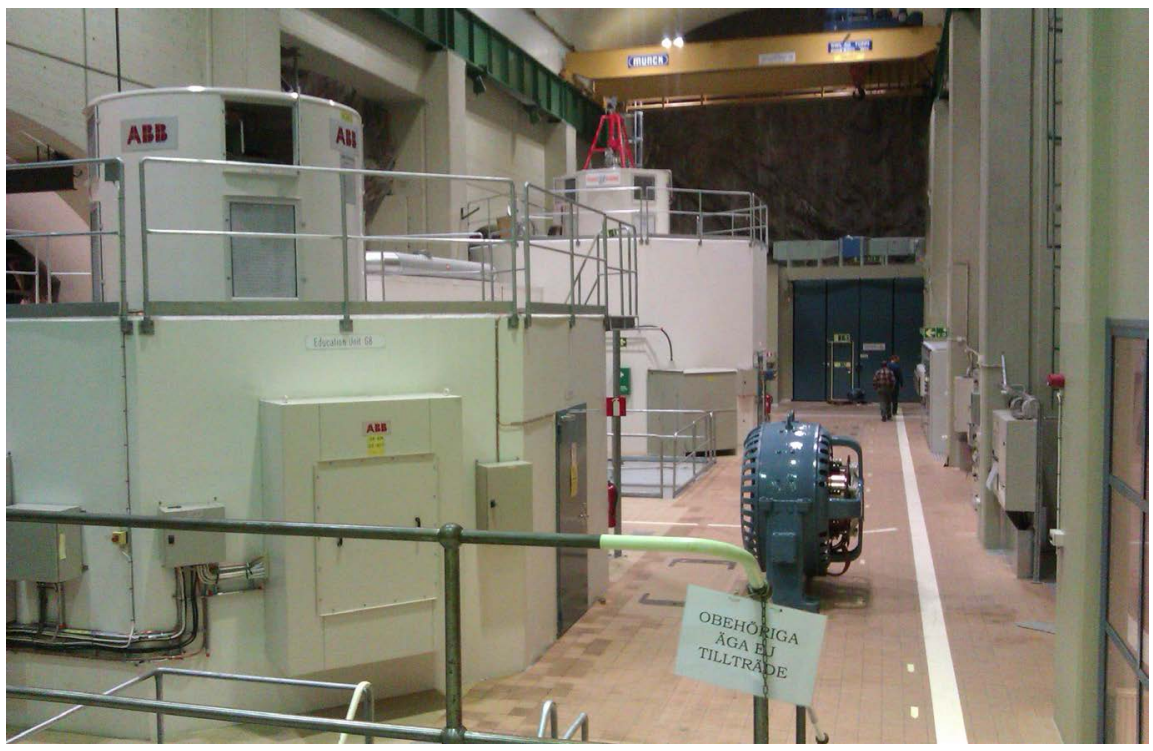

Figure 3. The two hydropower units at the Porjus research and education facility, the installation was performed on Francis unit U8 in the foreground.

Table 1. Rated values for the turbine-generator and dump-load.

\begin{tabular}{cc}
\hline Parameter & Value \\
\hline Generator rating & $11 \mathrm{MVA}, \cos \varphi=0.9$ \\
Generator Voltage & $10 \mathrm{kV}$ \\
Dump-load rating & $4 \mathrm{MVA}, \cos \varphi=1.0$ \\
Dump-load Voltage & $10 \mathrm{kV}$ \\
Turbine type & Francis \\
Guide vane closing time & $3.4 \mathrm{~s}$ \\
\hline
\end{tabular}

The threshold value for the deactivation of the dump-load during a load rejection and an emergency stop differs. During load rejection the unit should come back to synchronous speed as soon as possible, but during an emergency stop the unit should come to a complete halt.

\subsection{The Dump-Load Circuit Breaker}

The dump-load circuit breaker was a standard circuit breaker that could be closed and opened remotely using the signals from the control system. In the implementation the breaker used was an ABB SafeRing DeV, rated $12 \mathrm{kV}, 630 \mathrm{~A}$. It is a simpler distribution circuit breaker since the short circuit power is that of the generator and not the grid.

\subsection{The Dump-Load Used}

Finding a suitable dump-load is a big challenge. A robust off-the-shelf product would provide the most economical solution. The search ended up in the selection of a $4 \mathrm{MW}$ dump-load in the form of a electrode boiler, for the $10 \mathrm{MW}$ unit, shown in Figure 4 . The boiler consists of three electrodes surrounded by a 


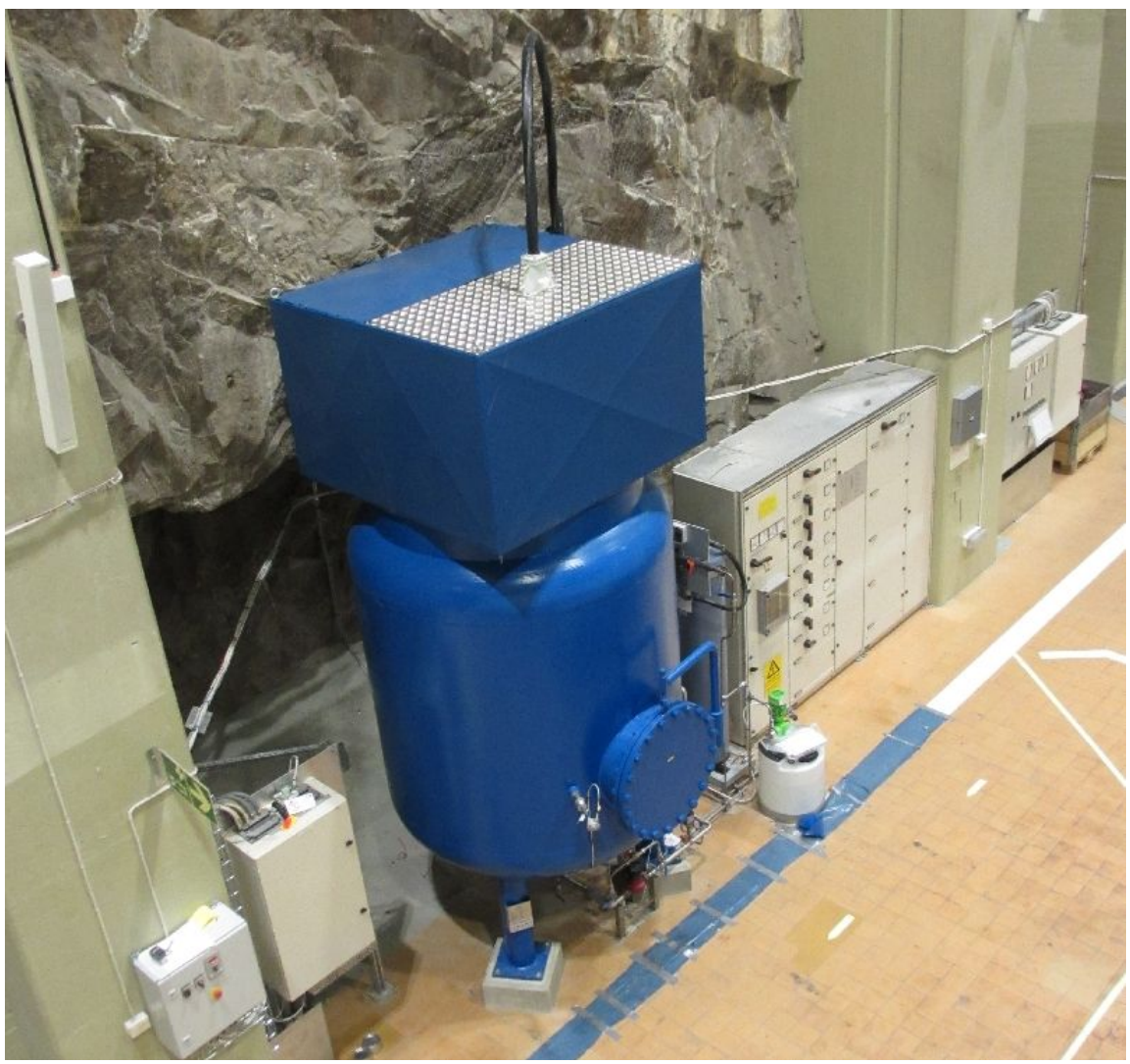

Figure 4. The $4 \mathrm{MW}, 10 \mathrm{kV}$ electrode boiler used as a dump-load in the tests.

potential equalizing cage. The whole setup is immersed in water of the right conductivity to give the correct power at rated voltage. This means that the power is developed in the water between the electrodes and the potential equalizing cylinder. The water volume of the boiler is $5.4 \mathrm{~m}^{3}$, which means that the 4 MW developed during the units $3.4 \mathrm{~s}$ closing time results in a global temperature increase of about $0.5^{\circ}$ Celsius in the dump load. The electrode boiler has no moving parts, and the power rating is tuned by adding a conductive salt to the water inside the boiler. To ensure the power uptake a small pump, to stir the water ensuring the water conductivity to be homogeneous, can be added.

\subsection{Measured Signals}

During the tests the electrical output and rotational speed were of particular interest. Besides these parameters, vibration levels and spiral casing pressure were measured. Measurements were taken from existing voltage and current transformers with high accuracy. Some signals, like the speed was extracted from the machine control computer and saved onto a file. The typical resolution of the voltage and current transformers is parts of percent. Since we are interested in relative values the accuracy is enough.

\section{Results}

The system was tested at $6 \mathrm{MW}$, and at $9 \mathrm{MW}$ of initial turbine power. Initially 
the power was directed to the grid and a trip signal was sent to the generator circuit breaker. The system was tested for load rejection and emergency stop triggered by different signals in the relay protection system.

The stator voltage will increase during the over speed due to the increased speed. The voltage regulator will aim to keep the voltage constant.

\subsection{Load Rejection}

During load rejection the guide vanes will start to close, after some time when the electrical frequency approaches the grid frequency the turbine governor will keep the unit in no-load operation and try to reconnect it to the grid. Load rejection can be triggered by e.g. a grid event.

In Table 2 the reduction in over speed for the dynamic braking is shown.

Figure 5 shows the armature voltage during the load rejection. The over-voltage is the result of the increased speed and the relatively slow rotating excitation system. When the load returns the armature voltage is stabilized. There is a potential to enhance the performance of the system by actively tuning the magnetization level of the synchronous generator.

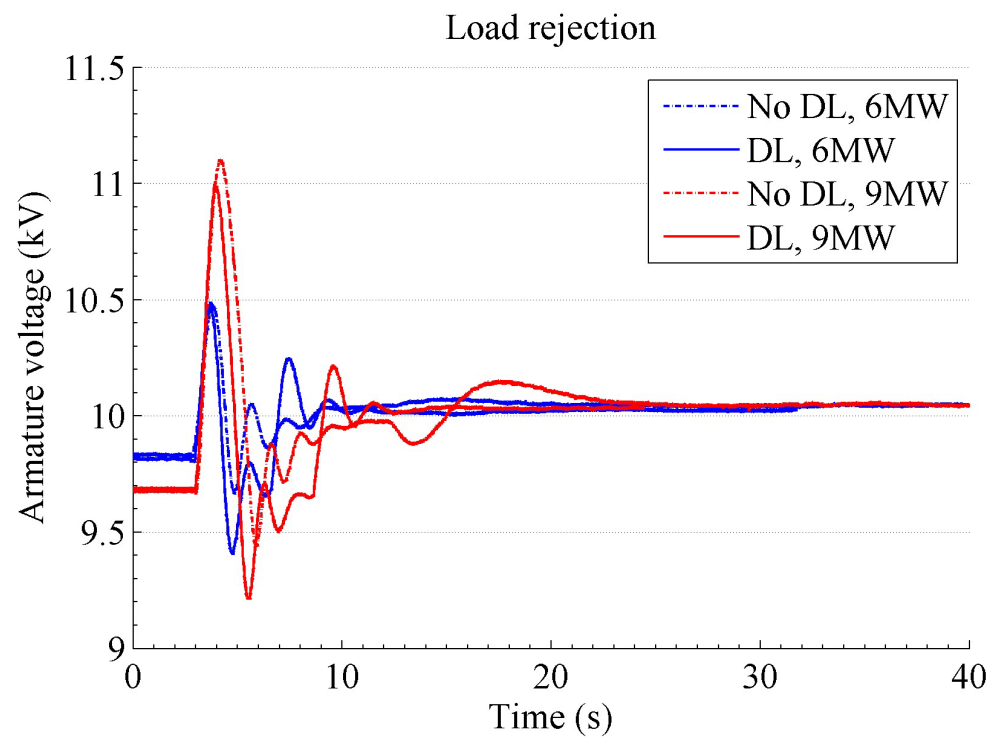

Figure 5. The armature voltage during the load rejection tests.

Table 2. The over speed behaviour using a dynamic breaking system on a $10 \mathrm{MW}$ unit equipped with a $4 \mathrm{MW}$ dump-load.

\begin{tabular}{ccccc}
\hline Test & Initial & Max & Over speed & Time to \\
\hline No DL & power & speed & reduction & max speed \\
DL & $6 \mathrm{MW}$ & $115.4 \%$ & & $3.5 \mathrm{~s}$ \\
No DL & $6 \mathrm{MW}$ & $111.4 \%$ & $25.3 \%$ & $3.1 \mathrm{~s}$ \\
DL & $9 \mathrm{MW}$ & $133.0 \%$ & & $3.8 \mathrm{~s}$ \\
\hline
\end{tabular}


In Figure 6 the power delivered to the dump-load can be seen. The power is fairly constant and could be further tuned by adding a controller that alters the magnetization level in order to control the power. This also means that it is possible to control the speed of the unit with the magnetization equipment.

The simulation in Figure 2 corresponds well with the measured shaft speed during load rejection, Figure 7, despite the fact that turbine is operated outside the Mussel diagram that is used in the simulation for the turbine energy absorption.

As can be seen in Figure 8 the relative vibration level measured on the turbine guide bearing is more than halved for the $9 \mathrm{MW}$ case.

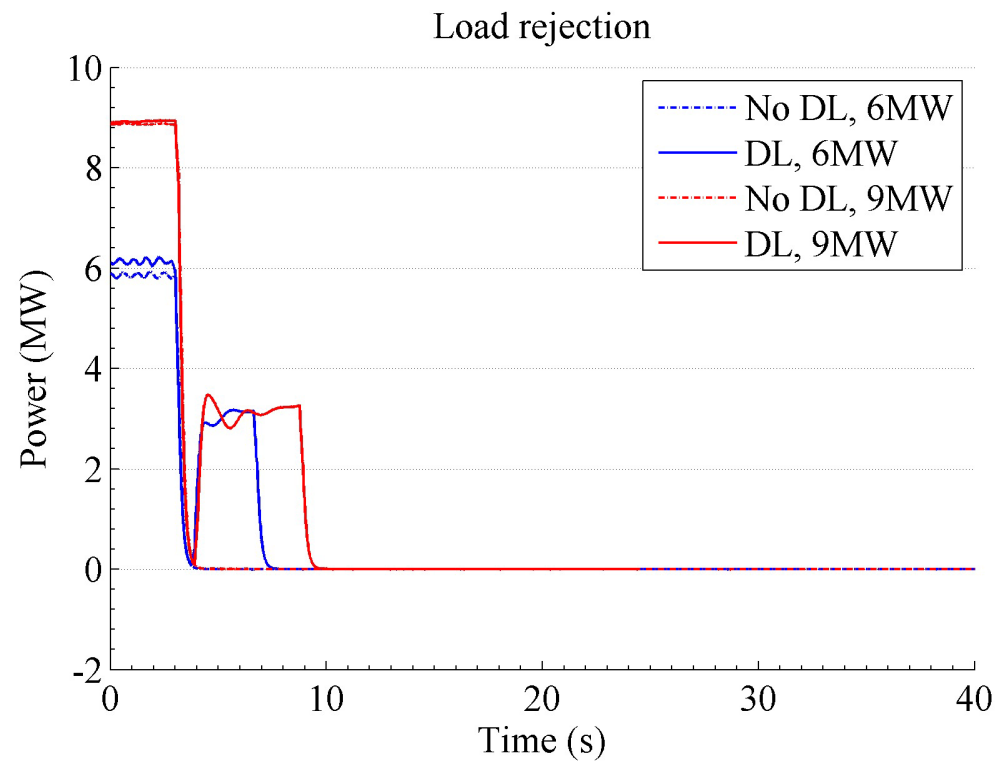

Figure 6. The electrical power measured during the tests.

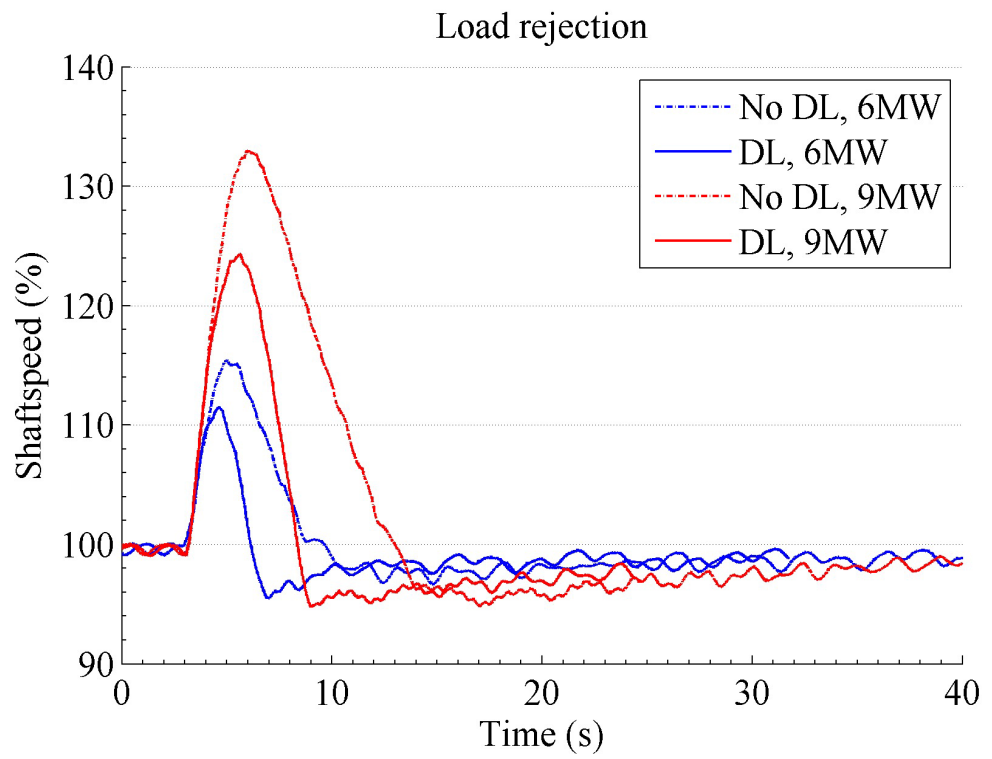

Figure 7. The shaft speed recorded during the tests. 
Load rejection

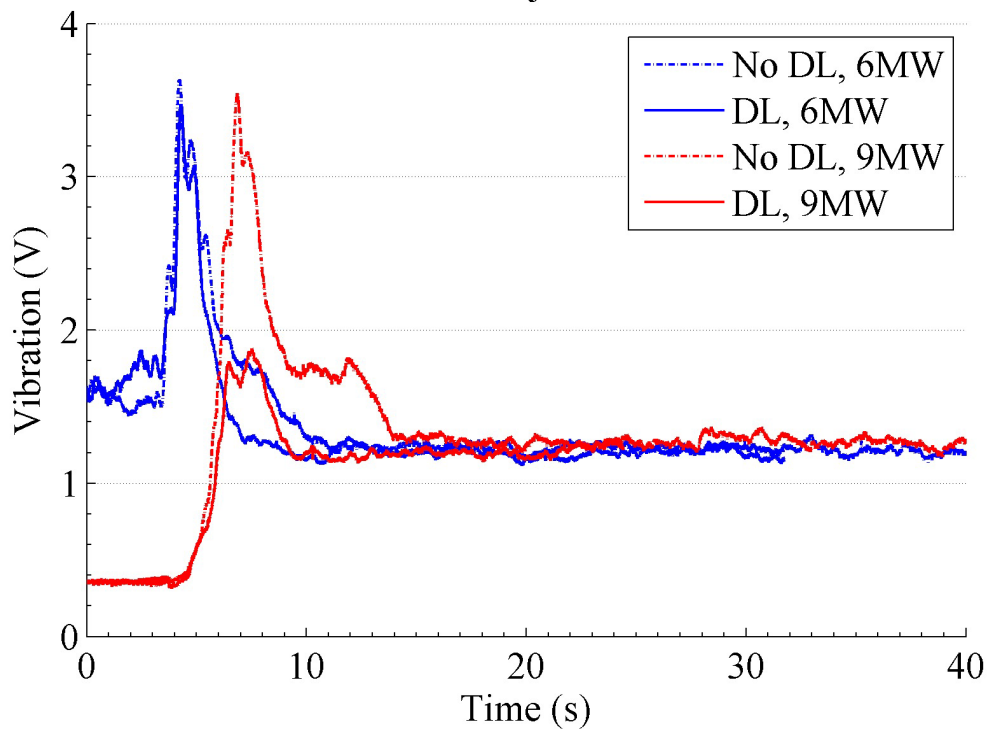

Figure 8. The vibration level recorded during the tests.

The pressure in the spiral case and draft tube was measured during the test, they show little change since the closing time of the guide vanes is unchanged, and the speed change then the dump load is activated did not alter the pressure to any large degree.

\subsection{Emergency Stop}

If a vibration sensor or any other sensor detects something more major the relay protection will call for an emergency stop to bring the turbine to complete standstill. The guide vanes will close completely.

\section{Relay Statistics for Activation Rate of a Braking Resistor}

Since the dynamic breaking system cannot be connected when there is an electrical fault in the generator, it is interesting to see how many times the braking resistor could be activated for a number of units. Statistics from a Swedish utility employing different types of turbines and very large spread in age and generations of electrical and mechanical equipment showed that out of 3052 instances when load rejection or emergency stopping was called for a dump load could have been activated in 2450 occasions. This represent more than $80 \%$ of all emergency actions.

\section{Outlook}

Since the braking resistor cannot be connected during an electrical stator insulation fault its scope of application in this regard is somewhat limited. However, if the load is continually cooled it can be used to enhance dam safety. Instead of building additional spillway capacity the idea of dispatching water through the turbine is an attractive one, since this removes the need to reduce the water 
speed after the outlet, uses existing equipment needs no additional backup power. This is the aim of a new project within a Swedish utility. The low cost of the load and circuit breaker should make it an attractive alternative to spillway capacity. It can be used as an emergency system that can activate quickly and save time compared to spillgate activation. The high heat capacity of water means that, if the river itself is used to cool the heat generated, only a very small temperature increase in the river can be detected. Continuous operation would mean that the magnetization equipment would control the voltage over the resistive load, and thereby the braking power on the shaft, i.e. speed control with the magnetization equipment. Questions regarding joint control of the turbine governor and magnetization equipment has then to be addressed. We will return to this question in a future article after the testing of such a system.

If the load is installed for dam safety purposes to safely discharge water when the external grid is lost it could also be used to reduce the overspeed during load rejection and emergency stop, as described in this paper.

\section{Conclusions}

This paper presents the results from an implementation of a dynamic braking system on a water turbine-generator system.

The results show a reduced over speed and stopping time and also reduced vibration levels.

An improved reduction of the over speed could be obtained by optimizing the behaviour of the magnetization equipment to keep the output power to the dump load constant when the speed changes.

It seems the best use of the verified installation would be to enhance Dam safety by using the dump-load in continuous mode operation as a replacement of using spill gates. This would require continuous cooling of the dump load. This will be described in a following article.

\section{Acknowledgements}

We thank the people at the Porjus foundation site and personnel from ABB that made the tests possible. Especially Gösta Uusitalo is remembered for his valuable help, and happy spirit.

\section{References}

[1] Kay, M. (2007) Practical Hydraulics. CRC Press.

[2] Kilbourne, C.E. and Terry, I.A. (1932) Dynamic Braking of Synchronous Machines. Electrical Engineering, 51, 406-409.

[3] Ellis, H.M., Hardy, J.E., Blythe, A. and Skooglund, J. (1966) Dynamic Stability of the Peace River Transmission System. IEEE Transactions on Power Apparatus and Systems, PAS-85, 586-600. https://doi.org/10.1109/TPAS.1966.291595

[4] Shelton, M.L., Winkelman, P.F., Mittelstadt, W.A and Bellerby, W.J. (1975) Bonneville Power Administration 1400-MW Braking Resistor. IEEE Transactions on Power Apparatus and Systems, 94, 602-611. https://doi.org/10.1109/T-PAS.1975.31888 
[5] IEEE Power System Engineering (1978) A Description of Discrete Supplementary Controls for Stability. IEEE Transactions on Power Apparatus and Systems, PAS97, 149-165. https://doi.org/10.1109/TPAS.1978.354466

[6] Grobovoy, A.A. (2001) Russian Far East Interconnected Power System Emergency Stability Control. Power Engineering Society Summer Meeting, 2, 824-829.

[7] Rahim, A.H.M.A. and Al-Maghraby, H.M. (2000) Dynamic Braking Resistor for Control of Subsynchronous Resonant Modes. IEEE Power Engineering Society Summer Meeting, 3, 1930-1935.

[8] Causebrook, A., Atkinson, D.J. and Jack, A.G. (2007) Fault Ride-Through of Large Wind Farms Using Series Dynamic Braking Resistors. IEEE Transactions on Power Systems, 22, 966-975. https://doi.org/10.1109/TPWRS.2007.901658

[9] Grobovoy, A.A. and Lizalek, N.N. (1998) Multiple Dynamic Brake and Power System emergency Control. 1998 International Conference on Power System Technology, Proceedings of the POWERCON98, 2, 1351-1355.

[10] Grobovoy, A.A., Dedukhina, E., Kosterin, V. and Lizalek, N. (2003) Third Generation System Protection Scheme Project for Zeya Hydro Power Plant. 17th International Conference on Electricity Distribution, Barecelona.

[11] Jeong, H.G. and Lee, K.B. (2014) A Control Scheme to Fulfill the Grid-Code under Various Fault Conditions in the Grid-Connected Wind Turbines. Electrical Engineering, 96, 199-210. https://doi.org/10.1007/s00202-013-0290-x

[12] Arshenevskii, N.N. and Sotnikov, G.G. (1989) Use of Electrical Braking of Units at Hydroelectric Stations When Dropping the Load. Hydrotechnical Construction, 23, 158-161. https://doi.org/10.1007/BF01427765 